\title{
Innovative Bioluminescence Resonance Energy Transfer Assay Reveals Differential Agonist-Induced D2 Receptor Intracellular Trafficking and Arrestin-3 Recruitment
}

\author{
Luc De Vries, Frédéric Finana, Claudie Cathala, Brice Ronsin, and Didier Cussac ${ }^{1}$
}

Central Nervous System Innovation Unit, CEPC Campans - Belair de Campans, Castres, France (L.D.V., F.F., C.C., D.C.) and CNRS, UMR5547, Centre de Biologie du Développement, Université de Toulouse III-Paul Sabatier, Toulouse, France (B.R.)

Received January 28, 2019; accepted June 19, 2019

\section{ABSTRACT}

The dopamine D2 receptor (D2R) mediates ligand-biased signaling with potential therapeutic implications. However, internalization, choice of endocytic routes, and degradation of the $\mathrm{D} 2 \mathrm{R}$ in lysosomes may also participate in agonist-directed trafficking. We developed bioluminescence resonance energy transfer (BRET) assays that measure relative distances between Renilla luciferase8-tagged D2R and green fluorescent protein 2 (GFP2)-tagged K-Ras (plasma membrane marker), and between luciferase8-tagged D2R and GFP2-Rab5 (early), GFP2-Rab4 (recycling), or GFP2-Rab7 (late) endosomal markers. The BRET signal between D2R-Luc and GFP2-K-Ras was robustly diminished after receptor internalization induced by dopamine, with subsequent BRET signals increasing when luciferase8tagged D2R approached GFP2-Rab proteins in endosomal compartments. All BRET signals were blocked by the selective D2R antagonist haloperidol and were decreased by low temperature and high sucrose blocks, two parameters interfering with internalization. Some antipsychotic drugs, such as aripiprazole, are less efficacious in internalizing D2R than most of the antiparkinsonian agents. However, antipsychotics were nearly as efficacious as antiparkinsonians in directing the D2R toward early and recycling endosomes. The Rab7 marker for the late endosome/lysosome route was also capable of discriminating between D2R compounds. We could show that some drugs engaged the D2R either to interact preferentially with arrestin-3 or to internalize. Our study revealed that D2R trafficking in cells was differentially regulated by antipsychotic and antiparkinsonian drugs. Taken together, the BRET assays reported here could further help decipher D2R ligand-induced arrestin-3 recruitment and trafficking, with potentially more selective therapeutic profiles and fewer undesired side effects.

\section{Introduction}

The desensitization and internalization of G-protein-coupled receptors (GPCRs) after pharmacological treatment likely contribute to the responsiveness of cells and can form part of the desired effect of a drug. There are several processes in which it becomes important to be able to predict the nature of GPCR trafficking upon binding to a ligand. One involves signal termination by endocytosis, i.e., how fast and in what proportion must a receptor be taken out of circulation to stop the action of a ligand on a cell, followed by recycling and/or degradation, which form part of the normal life cycle of most GPCRs (Ferguson, 2001). For many GPCRs, the chain of events from activation by a ligand to receptor internalization into endosomes and subsequent sorting and trafficking to the lysosome for degradation is relatively well known (Marchese et al., 2008). Receptor recycling back to the plasma membrane

\footnotetext{
${ }^{1}$ Current affiliation: Cussac Consulting, Arcachon, France.

https://doi.org/10.1124/mol.119.115998.
}

via recycling endosomes-the default pathway-is also well described, although the exact determinants on the receptor for slow, fast, or no recycling are less clear (Marchese et al., 2008). Trafficking of GPCR between intracellular compartments takes place via vesicular transport, with each compartment and each type of vesicle having their own specific protein markers. The small G-proteins of the Rab subfamily ( $>50$ members) are mostly involved in vesicular trafficking and often define a specific step, compartment, or vesicle population in this process (Barr, 2013). Classically, an internalized receptor leaves the plasma membrane at a clathrin-coated pit for an early endosome, defined by the presence of Rab5 (Bucci et al., 1992), among others (EEA1, SNX1). At this point, the receptor can recycle to the plasma membrane via fast recycling endosomes defined by Rab4 (van der Sluijs et al., 1992), or traffic toward late endosomes defined by Rab7 (Rink et al., 2005), en route for the lysosome.

The dopamine D2 receptor (D2R) is a GPCR target that is clinically relevant at least for antipsychotic and antiparkinson

ABBREVIATIONS: BRET, bioluminescence resonance energy transfer; $\mathrm{CHO}$, Chinese hamster ovary; DAPI, 4',6-diamidino-2-phenylindole; D2R, dopamine D2 receptor; GFP2, green fluorescent protein 2; GPCR, G-protein-coupled receptor; GRK2, G-protein receptor kinase 2; LSD 25 tartrate, (6aR,9R)-N,N-diethyl-7-methyl-4,6,6a,7,8,9-hexahydroindolo[4,3-fg]quinoline-9-carboxamide; Luc, luciferase; (+)-3-PPP, (R)-3-(1-propylpiperidin3-yl)phenol; (-)-3-PPP, S(-)-3-(3-hydroxyphenyl)-N-n-propylpiperidine; SLV313, (1-(2,3-dihydro-benzo[1,4]dioxin-5-yl)-4-[5-(4-fluoro-phenyl)pyridin-3-ylmethyl]-piperazine monohydrochloride); SSR181507, (3-exo)-8-benzoyl- $N$-[[(2S)7-chloro-2,3-dihydro-1,4-benzodioxin-1-yl]methyl]-8azabicyclo-[3.2.1]octane-3-methanamine monohydrochloride. 
drugs which are capable of blocking or stimulating this receptor, respectively. Downregulation of the D2R, including by receptor internalization, might be a valid pharmacological approach to treat schizophrenia (Tsai, 2004). Ligandmediated D2R modulation of the arrestin-3 pathway may be of interest for antipsychotic efficacy, although a debate still exists on whether blockade or, rather, stimulation of this pathway is therapeutically favorable (Beaulieu et al., 2007, 2008; Masri et al., 2008; Allen et al., 2011; Park et al., 2015). Arrestin-2 or arrestin-3 (previously called $\beta$-arrestin1 or $\beta$-arrestin2) recruitment by GPCRs has been described as a general feature of the internalization process (Ménard et al., 1997), and recently, ligand-induced biased activation of both G-protein and arrestin pathways was also observed for the adrenergic $\alpha_{2 \mathrm{C}}$ receptor (Kurko et al., 2014), among other GPCRs (Stallaert et al., 2011; Luttrell et al., 2015). A specific D2R mutant failed to internalize, although it was still capable of interacting with arrestin-3, suggesting again that both mechanisms may be disconnected in particular conditions of receptor conformation (Clayton et al., 2014). Dissociation of G-protein and arrestin-3-dependent pathways was also obtained for the D2R by applying the evolutionary trace method to generate pathway-specific signaling mutants of this receptor (Peterson et al., 2015). Recently, it was quite convincingly shown that GPCR signaling requires G-proteins but not arrestins, and that the role of arrestins is limited to the formation of protein scaffolding complexes rendering signaling more efficient without having a specific signaling function (Grundmann et al., 2018). Previous reports already pointed out that arrestins were dispensable for GPCR signaling toward extracellular signal-regulated kinase activation (Alvarez-Curto et al., 2016; O'Hayre et al., 2017). Using a time-consuming ELISA-based assay, we previously studied D2R internalization induced by antipsychotic compounds having dual 5-HT1A/D2 properties, such as aripiprazole (Heusler et al., 2008). The purpose of the present study was to extend our previous observations for a large series of antipsychotic and antiparkinsonian drugs, and to examine whether certain D2R ligands can differentially drive the internalized receptor toward recycling or degradation compartments. Based on a study regarding $\beta 2$-adrenergic receptor trafficking (Lan et al., 2011), we developed new bioluminescence resonance energy transfer (BRET) assays that can measure the change in relative distances between the $D 2 R$ and small G proteins, such as Ras as a specific marker of plasma membrane localization and Rab5, Rab4, and Rab7 as specific markers of early, recycling, and late endosomal/ lysosomal compartments, respectively.

Our results allow us to discuss the behavior of the drugs inducing D2R trafficking in living cells and to compare these characteristics with that of arrestin-3 recruitment in the same cellular environment.

\section{Materials and Methods}

DNA Constructs. The short splice variant of the human D2R cDNA, inserted in pCR3.1 mammalian expression vector as previously described (Pauwels et al., 2001), was subcloned into the vector coding for the variant of Renilla luciferase [pRLuc(h)8]. Fusion was realized at the $\mathrm{C}$ terminus of the receptor. $\mathrm{p} R \mathrm{Luc}(\mathrm{h}) 8$ was made by directed mutagenesis on the vector $\mathrm{p} R$ luc(h)-N3 (PerkinElmer Life Sciences) using the Multi Site Directed Mutagenesis Kit from Stratagene
(Agilent, Santa Clara, CA). Eight amino acids were changed (A55T, C124A, S130A, K136R, A143M, M185V, M253L, and S287L), because these mutations yield enhanced and stabilized emission signals from the luciferase (Loening et al., 2006).

A full-length K-Ras2A (NM_033360/P01116-1) fragment was polymerase chain reaction-amplified on human brain cDNA with specific primers, cloned into pCR2.1 TOPO for sequence verification, and then subcloned into pGFP2-Rluc(h) by replacing the Rluc(h) insert.

The cDNA corresponding to the $\mathrm{C}$ terminus of human K-Ras2B (K-Ras2Bct, amino acids R164 to M188), amplified by polymerase chain reaction on the full-length cDNA of the human K-Ras2B isoform (NM_004985.4/P01116-2) and inserted in pCR2.1 TOPO vector, was subcloned into the vector coding for green fluorescent protein 2 (GFP2) [pGFP2-Rluc(h); PerkinElmer Life Sciences] by replacing the $R$ luc(h) insert, so that the fusion was located at the $\mathrm{N}$ terminus of K-Ras.

The cDNAs coding for full-length human Rab5A, Rab4, and Rab7A, inserted in the pCR2.1 TOPO vector, were subcloned into the vector coding for GFP2 [pGFP2-Rluc(h)] by replacing the $R$ luc(h) insert, so that the fusions were located at the $\mathrm{N}$ termini of the Rab proteins. The cDNA coding for the GFP2-(h)arrestin-3 fusion (from pGFP2-arrestin-3; PerkinElmer Life Sciences) was subcloned in pcDNA3.1 vector. Finally, the cDNAs encoding human arrestin-3 and G-protein receptor kinase 2 (GRK2) were inserted in pcDNA3.1 vector.

The nucleotide sequences were fully verified by DNA sequencing using the BigDye Terminator V1.1 Cycle Sequencing Kit (Applied Biosystems, Foster City, CA).

Cell Culture and Transfection. Chinese hamster ovary (CHO) cells were cultured in F-12 nutrient mixture (Ham's medium) supplemented with $10 \%$ (v/v) FBS, $2 \mathrm{mM}$ L-glutamine, penicillin $(100 \mu \mathrm{g} / \mathrm{ml})$, and streptomycin $(100 \mu \mathrm{g} / \mathrm{ml})$ at $37^{\circ} \mathrm{C}$ in a humidified atmosphere at $5 \% \mathrm{CO}_{2}$.

For transient expression of Rluc8-tagged D2R receptor, GFP2tagged GTPase proteins (K-Ras, Rab5a, Rab7a, Rab4), GFP2-tagged arrestin-3, and arrestin-3 and GRK2 proteins, cells were seeded in 100 -mm Petri dishes at a density of $5 \times 10^{6}$ and cultured for 24 hours. Transient transfections were performed using Lipofectamine 2000 reagent (Invitrogen, Carlsbad, CA) according to the manufacturer's protocol, with a ratio of $1 \mu \mathrm{l}$ of Lipofectamine for $1 \mu \mathrm{g}$ of DNA. This resulted in approximately 50\% transfection efficiencies. Plasmids were cotransfected with a ratio of 1:40 for D2s:K-Ras, 1:24 for D2s: Rab5, 1:30 for D2s:Rab4, 1:80 for D2s:Rab7, and 1:8 for D2s:arrestin-3. The total amount of cotransfected BRET-partner plasmids was $10 \mu \mathrm{g}$. Two micrograms of each expression plasmid for GRK2 and arrestin-3 was added per dish, except for the GFP2-arrestin-3 assays in which the extra arrrestin-3 was omitted. Twenty-four hours after transfection, cell medium was removed and replaced by fresh complete medium. Care was taken to use identical total amounts of plasmid in each comparative experiment by compensating with empty cytomegalovirus promoter-containing plasmid. For background BRET signal measurements, cells were transiently transfected with the donor construct in the absence of the acceptor construct.

BRET Measurements/Cell Preparation. Forty-eight hours after transfection, cells were washed twice with PBS plus $1 \mathrm{~g} / \mathrm{l}$ glucose, detached with PBS plus $3 \mathrm{mM}$ EDTA, and resuspended in PBS plus $1 \mathrm{~g} / \mathrm{l}$ glucose. A DC protein measurement assay was performed according to the manufacturer's protocol. For BRET monitoring (Ras and Rab), cells were distributed (70 $\mu \mathrm{g}$ of protein equivalent per well) in a 96-well microplate (OptiPlate; Costar, Corning Corporation) and incubated for 1 hour at $37^{\circ} \mathrm{C}$ in the presence of various ligands before substrate addition, except for shorter time-course experiments. For the D2R-Rluc8/GFP2-arrestin-3 BRET interaction assay, cells were incubated for 8 minutes with ligands before substrate addition. All ligands were solubilized at $10 \mathrm{mM}$ in DMSO; final DMSO concentrations in experiments never exceeded $0.1 \%$. Antagonists were added 5 minutes before agonist injection. BRET between Rluc8 and GFP2 was measured immediately after the addition of the $R$ luc 8 substrate coelenterazine $400 \mathrm{a}$ (5 $\mu \mathrm{M}$ final). 
BRET Measurements/Assay. BRET signals were collected using a Mithras LB940 instrument (Berthold, Bad Wildbad, Germany), allowing integration of successive signals detected in the 370- to 450-nm (Rluc8) and 495- to 535-nm (GFP2) windows with appropriate filters. Time of integration of 1 second was used for measuring photons emitted by Rluc 8 or by GFP2 fluorescent protein. All measurements were performed on duplicate wells, except for concentration-response and time-course studies, where single well measurements were taken in at least three independent experiments. We obtained the BRET signal by calculating the ratio of the energy emitted by GFP2 over the energy emitted by Rluc8. BRET signal values were corrected by subtracting the BRET background signal obtained in cells expressing the Rluc8-tagged construct alone from the BRET signal obtained in cells coexpressing Rluc8- and GFP2-tagged constructs (BRET net). A total luminescence readout was performed to ensure equal expression levels of $R$ luc8-tagged receptor between assays, containing or not containing the acceptor partner, and DNA quantity was adjusted to be transfected accordingly. For total luminescence, cell samples $(70 \mu \mathrm{g})$ were incubated in $5 \mu \mathrm{M}$ coelenterazine $\mathrm{h}$, and luminescence was measured 9 minutes after substrate addition, using the same instrument equipped with an emission filter at $480 \mathrm{~nm}$ and using a time of integration of 1 second.

Confocal Microscopy. CHO cells were transfected with $10 \mu \mathrm{g}$ of plasmid coding for marker GFP2 fusion protein (close to the amounts used in cotransfections; see ratios in the previous section) in 100-mm Petri dishes as described earlier and replated in chamber wells the next day. Forty-eight hours post-transfection, cells were fixed with paraformaldehyde [2\% (w/v), 30 minutes], labeled with 4',6-diamidino-2-phenylindole (DAPI) for nuclei localization, and mounted in Mowiol 4-88 [10\% (w/v)]. They were imaged using a Zeiss 710 confocal microscope with a $63 \times$ oilimmersion objective in sequential mode with specific dichroic mirrors for each configuration. Fluorescence emissions were collected with spectral windows between 414 and $488 \mathrm{~nm}$ for DAPI, and between 493 and $551 \mathrm{~nm}$ for GFP2. All images were taken at a size of $512 \times 512$ pixels.

Data and Statistical Analysis. All data analyses were performed using GraphPad Prism 4 software for Windows (GraphPad Software, San Diego, CA) and represent the mean \pm S.D. of three or more independent experiments. Concentration-response curves were fitted by nonlinear regression. Specifics of the statistical tests used are detailed in each figure legend, when appropriate.

Materials and Reagents. Coelenterazine $\mathrm{h}$ and 400a were purchased from Interchim (Montluçon, France). Ethylenediaminetetraacetic acid (EDTA) was purchased from Sigma-Aldrich (St. Louis, MO). F-12 nutrient mixture (Ham's medium), PBS (plus $1 \mathrm{~g} / \mathrm{l}$ glucose), Lipofectamine 2000 reagent, and DAPI were obtained from Invitrogen. The DC Protein Assay was from Bio-Rad (Hercules, CA). Mowiol 4-88 was purchased from Calbiochem (Darmstadt, Germany).

Dopamine hydrochloride, haloperidol, quinelorane, quinpirole, bromocriptine, (-)-3-PPP [S(-)-3-(3-hydroxyphenyl)- $N$-n-propylpiperidine], apomorphine, pergolide mesylate, piribedil, (+)-3-PPP [(R)-3(1-propylpiperidin-3-yl)phenol], and ropinirole were purchased from Sigma RBI (St. Quentin Fallavier, France). Clozapine was purchased from Tocris (Illkirch, France). Lisuride hydrogen maleate, roxindole, and terguride were obtained from Merck (Darmstadt, Germany). Talipexole was from Boehringer Ingelheim (Ingelheim am Rhein, Germany). Aripiprazole, bifeprunox, $N$-desmethyl clozapine, sarizotan hydrochloride, SSR181507 [(3-exo)-8-benzoyl- $N$ [[(2S)7-chloro-2,3-dihydro-1,4-benzodioxin-1-yl]methyl]-8-azabicyclo-[3.2.1] octane-3-methanamine monohydrochloride], SLV313 (1-(2,3-dihydro-benzo[1,4] dioxin-5-yl)-4-[5-(4-fluoro-phenyl)-pyridin3-ylmethyl]-piperazine monohydrochloride), and LSD 25 tartrate ((6aR,9R)- $N, N$-diethyl-7-methyl-4,6,6a ,7,8,9-hexahydroindolo[4,3-fg] quinoline-9-carboxamide) were synthesized intra muros (Centre de Recherche Pierre Fabre, Castres, France). Drugs were dissolved in $100 \%$ DMSO at $10^{-2} \mathrm{M}$ and subsequent dilutions were prepared in PBS plus $1 \mathrm{~g} / 1$ glucose.

\section{Results}

Validation of the D2R/K-Ras/Rab BRET2 System. The BRET2 system we developed here is based on the change in distance of a population of D2Rs-induced by D2R-specific ligands-versus a group of cellular markers located on the plasma membrane or on intracellular/vesicular membranes (Fig. 1A). The carboxy terminus of the D2R was fused to the energy donor Renilla luciferase, modified by eight mutations to enhance its emission (Rluc8; Loening et al., 2006). For the Ras marker on the plasma membrane or the Rab markers on endocytic vesicle membranes, the energy acceptor GFP2 was fused to the $\mathrm{N}$ terminus of the small G-proteins (see Materials and Methods for details), because their $\mathrm{C}$ termini are important for membrane anchoring. Each D2R/marker protein couple for BRET2 has its own basal BRET signal and should be considered as an independent assay. Upon ligand-induced internalization, the mean distance of the population of $\mathrm{D} 2 \mathrm{R}$ to the plasma membrane should increase, and thus the energy transfer (= BRET ratio) from receptor to plasma membrane marker (K-Ras) should decrease (Fig. 1A). As the receptors enter the endocytic pathway, their mean distance to endocytic vesicle markers should decrease, leading to an increased energy transfer from receptor to the markers Rab5, Rab7, and Rab4 (Fig. 1A). To verify the localization of the marker proteins for the BRET assays, we performed confocal microscopy analysis on fixed CHO cells transiently transfected with GFP2-marker protein fusions. Transfection efficiencies of $>50 \%$ were regularly observed (data not shown). Images for GFP2-K-Ras were mainly concordant with plasma membrane localization, whereas for GFP2-Rab5, GFP2-Rab4, and GFP2Rab7, the localization signals were distinct, clearly vesicular, and reminiscent of endosomal compartments (Fig. 1B).

To obtain robust BRET assays that report internalization and trafficking of the D2R, we first optimized the assays by varying the expression levels and the ratios of our BRET2 probes (data not shown). Typically, $0.25 \mu \mathrm{g}$ of $\mathrm{D} 2 \mathrm{R}$ receptor plasmid (donor) and 6-10 $\mu \mathrm{g}$ of Ras/Rab marker plasmid (acceptor) provide the most important BRET signal decrease or increase for Ras or Rab proteins, respectively. We then performed time-course experiments for each of the four markers after dopamine-induced internalization. Whereas we observed a decrease in BRET signal starting from the first minute with Ras, longer times were necessary to detect the increase in BRET signal for Rab5 and Rab7, with Rab4 exhibiting the longest delay (Fig. 2). However, dopamine induced a maximal change in BRET signal after 60 minutes of stimulation for all markers, and this time point was retained for all subsequent experiments.

In other optimization experiments, we compared the fulllength K-Ras2A isoform, fused at its $\mathrm{N}$ terminus to GFP2, to the truncated form of K-Ras2B (K-Ras2Bct, the C-terminal 25 amino acids of K-Ras2B), also fused at its $\mathrm{N}$ terminus to GFP2, as used previously (Lan et al., 2011). The K-Ras2Bct isoform supposedly allows a more focalized localization on the plasma membrane (see Discussion for more details). We also studied the coexpression of GRK2 and arrestin-3 together with our BRET probes, as it is known that GRK2/arrestin-3 expression can enhance GPCR internalization. Transient expression of D2s-Rluc8 with GFP2-K-Ras2A in CHO cells, followed by a 1hour treatment with dopamine $(1 \mu \mathrm{M})$, induced a large decrease in BRET signal ( $\triangle \mathrm{BRET}$ value of -0.087 ; Fig. $3 \mathrm{~A})$. 
A

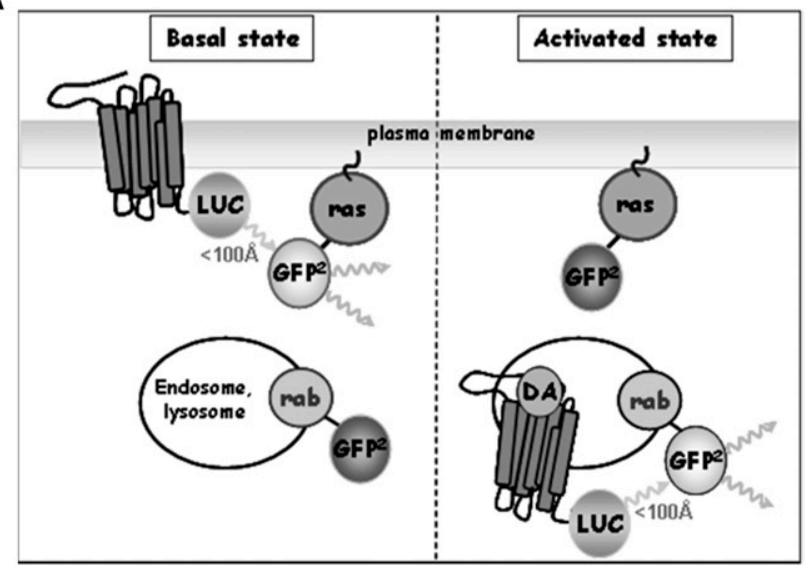

B
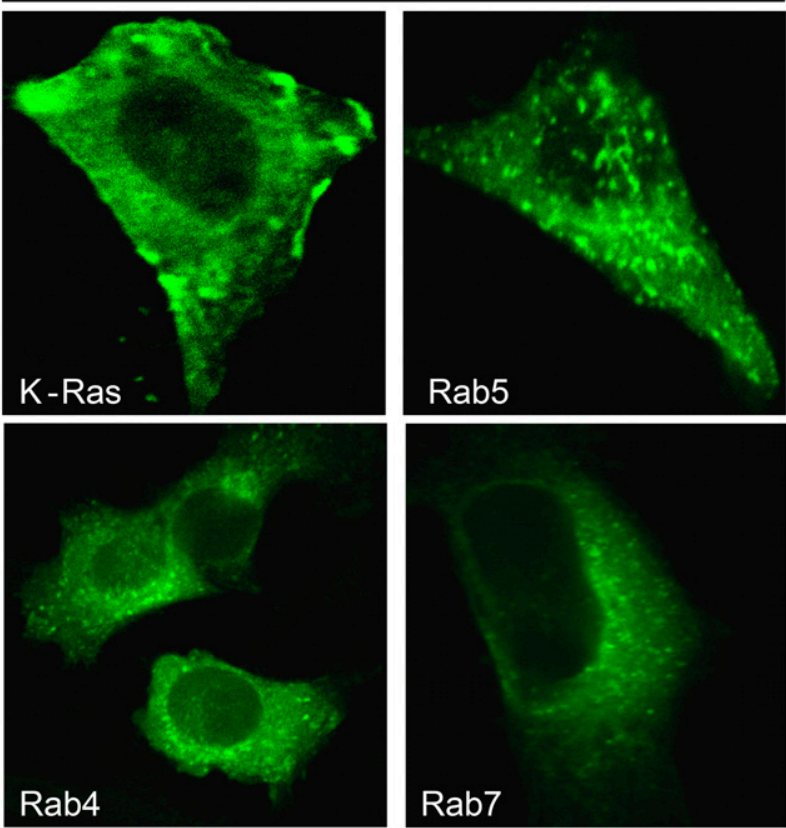

Fig. 1. Schematic representations of the cellular D2R/K-Ras and D2R/Rab BRET2 internalization assays and localization of the marker proteins. (A) $\mathrm{D} 2 \mathrm{R} / \mathrm{K}$-Ras assay. Ligand-induced internalization of the D2R leads to separation from the plasma membrane, increasing its distance from the K-Ras marker protein located at the plasma membrane. Renilla luciferase (LUC) fused to the C terminus of the D2R emits light at $400 \mathrm{~nm}$ upon consumption of its cell-permeable substrate coelenterazine 400a. When in close proximity, this light is captured via energy transfer (BRET) by the GFP2 moiety fused to K-Ras, which causes additional light emission at $510 \mathrm{~nm}$. The decrease of BRET signal-measured as the ratio of 510-nm light over 400-nm light-generally reflects an increase in the distance between the BRET partners. D2R/Rab assays. .The reasoning is the same as for the D2R/K-Ras assay but here the Rab5, Rab7, and Rab4 marker proteins-fused to GFP2 - are located on different intracellular endocytic vesicles. Internalization of the D2R decreases its distance toward these marker proteins on the vesicles, leading to an increase of the BRET signal. (B) Localization of K-Ras2Bct-, Rab5-, Rab7-, and Rab4-GFP2 fusion marker proteins by confocal microscopy. CHO cells expressing the marker protein were handled as described in Materials and Methods. For K-Ras2Bct, we observe patched plasma membrane signals. Punctate signals for Rab5, Rab7, and Rab4 indicate their presence on intracellular vesicles.

However, replacing full-length K-Ras2A with truncated K-Ras2Bct appeared to make a major contribution toward an enhanced difference in BRET signal, with a huge decrease in BRET signal after dopamine treatment ( $\triangle \mathrm{BRET}$ value of 0.387 ). In the presence of arrestin-3 and GRK2 coexpression, the negative BRET signal induced by dopamine using the
K-Ras2Bct probe is significantly increased (Fig. 3B). By contrast, performing the assay at $37^{\circ} \mathrm{C}$ did not significantly affect the BRET signal when compared with room temperature (Fig. 3B). Consequently, we performed all further experiments with the K-Ras2Bct probe including arrestin-3/GRK2 coexpression in our BRET/internalization assays.

To ensure that our assay correctly addresses the internalization process, we also tested the effect of low temperature and sucrose blocks. Indeed, clathrin-dependent internalization of GPCRs is sensitive to hypertonic sucrose (400 mM), and initiation of endocytic trafficking is inhibited by low temperatures $\left(4^{\circ} \mathrm{C}\right)$. Pretreatment of the cells with $400 \mathrm{mM}$ sucrose or lowering the temperature at $4^{\circ} \mathrm{C}$ reduced the dopamineinduced BRET signal by $24 \%$ and $51 \%$, respectively (Fig. 4). Similar results were obtained with the endosomal markers Rab5 and Rab4, although lowering the temperature exhibited more dramatic effects than sucrose implementation in these cases (Fig. 4). These results validate our GFP2-marker fusion proteins for use in BRET assays, as they seem to locate correctly and reflect the true process of agonistinduced internalization and endocytic trafficking of the D2R in living cells.

Survey of a Large Series of Ligands Using the D2R/ K-Ras2B/Rab BRET2 System. We started by checking that the BRET measurements for the detection of D2R internalization and its trafficking through the endocytic pathways displayed sufficient sensitivity for the pharmacological examination of D2R ligands. Dopamine induced a robust decrease of BRET units in the D2R/K-Ras2Bct plasma membrane marker system, whereas aripiprazole behaved as a D2 partial agonist, as reported in other assays (Bruins Slot et al., 2006; Urban et al., 2007; Heusler et al., 2008; Klewe et al., 2008; Allen et al., 2011) (Fig. 5). The selective dopamine D2 antagonist haloperidol had no effect by itself but completely antagonized the dopamine effect. Similar pharmacological validations were obtained for the early endosome Rab5 and fast recycling endosomal Rab4 markers, with a relatively strong amplitude of the dopamine-induced BRET signal (Fig. 5). By contrast, the late endosome D2R/Rab7 BRET assay showed weaker amplitude increases by dopamine, but as before, aripiprazole behaved as a partial agonist and haloperidol completely blocked dopamine stimulation. Concentration-response studies derived from these assays showed that dopamine and aripiprazole exhibited similar potencies, whatever the markers used (values between 5 and $20 \mathrm{nM}$; Fig. 5).

Furthermore, the robust amplitude of BRET signal for the K-Ras2Bct probe allowed us to perform concentrationresponse studies for a large series of D2 ligands. The antipsychotic RGH188 (cariprazine) and the preclinical compound SSR181507 exhibited potencies and efficacies similar to aripiprazole, whereas $3 \mathrm{PPP}(-)$ [the $(-)$ enantiomer of preclamol] showed similar efficacy in internalizing the D2R but with much lower potency (Fig. 6A; Table 1). Bifeprunox was more efficacious than aripiprazole but with similar potency. Interestingly, the $(+)$ enantiomer of preclamol [3PPP $(+)]$ almost behaved as a full agonist, thus being closer to antiparkinsonian responses. Although sarizotan had been developed for Parkinson's disease, its profile-showing weak efficacy at the $\mathrm{D} 2 \mathrm{R}$ in this model-suggests it would be more appropriate to categorize this molecule as a potential antipsychotic.

Overall, known or potential antiparkinsonian drugs tested with the K-Ras2Bct probe exhibited almost full efficacy 

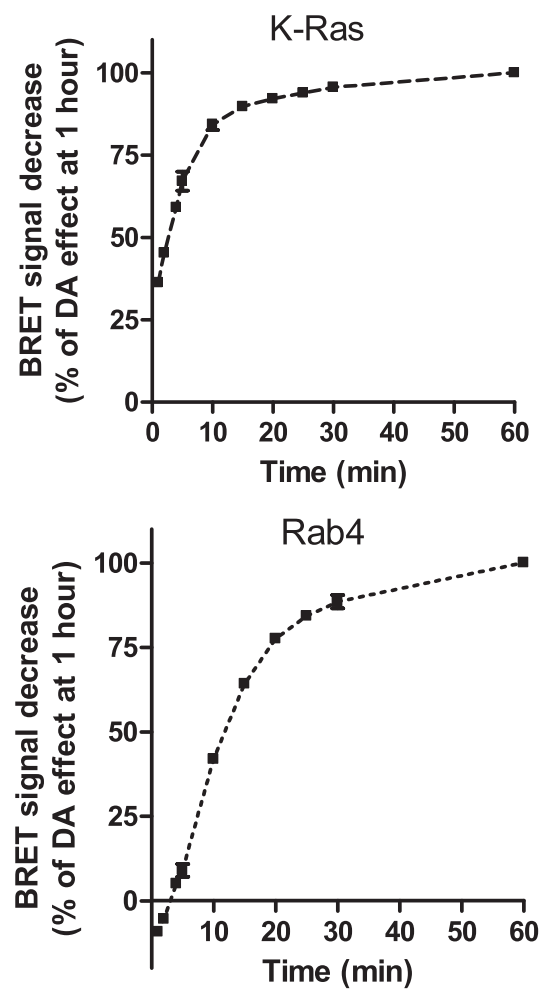
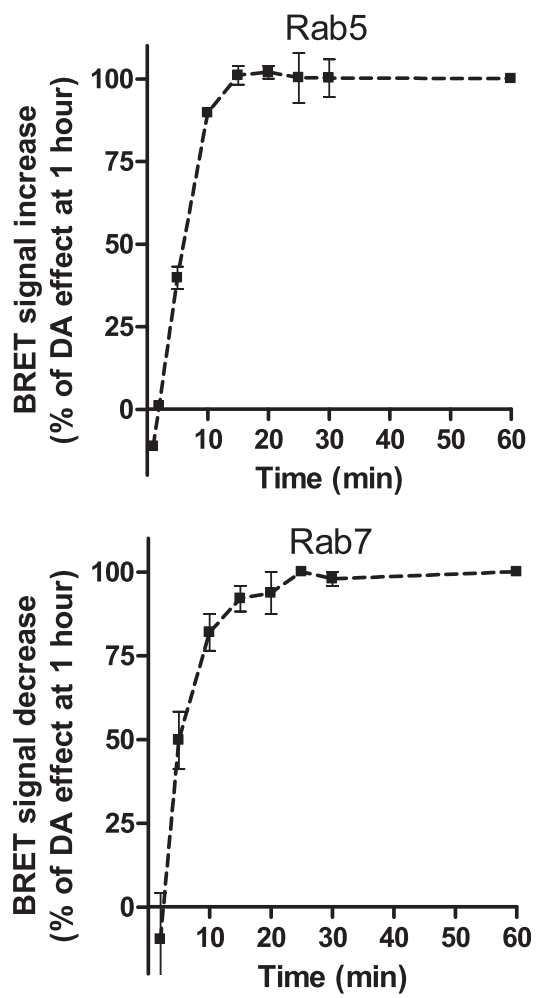

Fig. 2. Time-course analyses. $\mathrm{CHO}$ cells expressing D2R/K-Ras2Bct，D2R/Rab5，D2R/Rab7，or D2R/Rab4 BRET partners were incubated with $1 \mu \mathrm{M}$ dopamine, and BRET signals were measured at the indicated time points up to 1 hour. Data are expressed as percentage of the BRET signal induced by dopamine (DA) at 1 hour. Three independent time-course experiments were performed for K-Ras2Bct and Rab4, and two independent time-course experiments were performed for Rab5 and Rab7. compared with dopamine, with the exception of lisuride (86\%), roxindole $(80 \%)$, and terguride $(66 \%)$ (Fig. 6A; Table 1). Interestingly, the relatively partial efficacies of these latter compounds were counterbalanced by their high potencies, suggesting that low concentrations of these three drugs were sufficient to efficiently internalize the D2R. For the other antiparkinson agents with similar high efficacies, the rank order of potency was as follows: pergolide $>$ quinelorane $\approx$ apomorphine $>$ talipexole $\approx$ piribedil $>$ quinpirole $\approx$ ropinirole $\approx$ bromocriptine (Fig. 6A; Table 1).
A

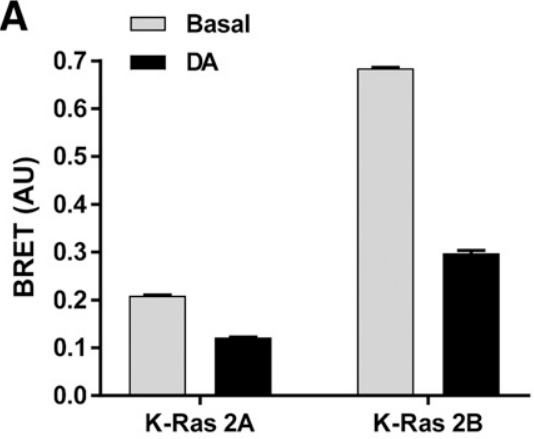

B

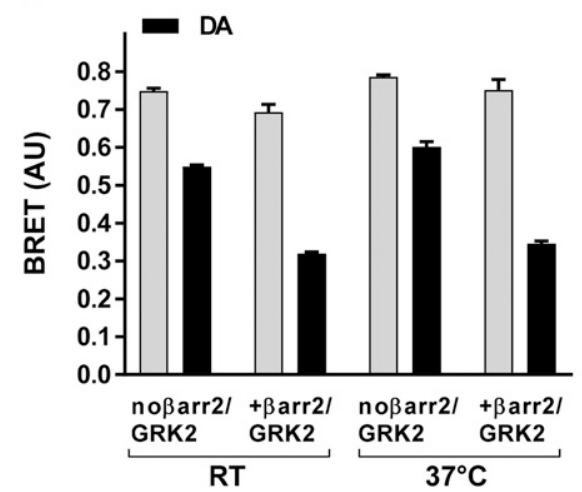

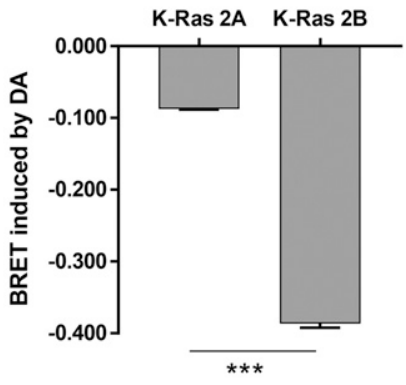

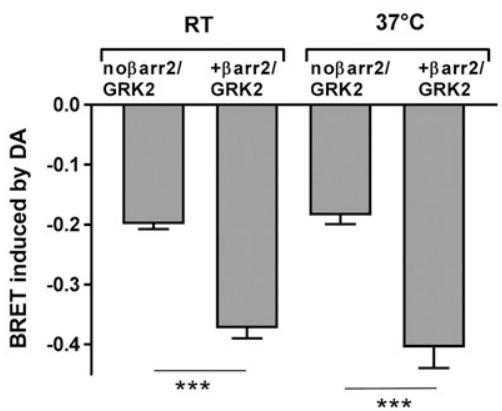

Fig. 3. Optimization experiments for the K-Ras BRET internalization assay. (A) Comparison of agonistinduced BRET signals from D2R/full-length K-Ras2A partners and D2R/C terminus K-Ras2B partners. We observe enhancement of basal BRET signal, but more importantly, an enhanced dopamine (DA)-induced amplitude of the BRET signal in the case of the C-terminal K-Ras2B (K-Ras2Bct) plasma membrane marker. These experiments were performed twice with duplicate measurements. (C) representation of the $\triangle B R E T$ signal (= ligand-induced BRET) from the data shown in (A). (B) Coexpression of arrestin-3 and GRK2 with BRET partners luciferase8-tagged D2R and K-Ras2Bct does not modify basal BRET but significantly amplifies dopamine-induced BRET. Incubations at $37^{\circ} \mathrm{C}$ did not enhance the BRET signals compared with room temperature. These experiments were performed three times with duplicate measurements. (D) Representation of the $\triangle$ BRET signal (= ligand-induced BRET) from the data shown in (B). The S.D. difference between $2 \mathrm{~A}$ versus 2 Bct conditions was submitted to a multiple $t$ test (Holm-Sidak), resulting in $t=71.03$ and $P<0.001$. Twotailed unpaired $t$ tests were performed for room temperature (RT) versus $37^{\circ} \mathrm{C}$ and $\pm \beta$-arrestin conditions, resulting in $\mathrm{df}=10, t=22.52$, and $P<0.001$ for the former and $\mathrm{df}=10, t=14.39$, and $P<0.001$ for the latter. $* * * P<0.001$. AU, arbitrary units. 

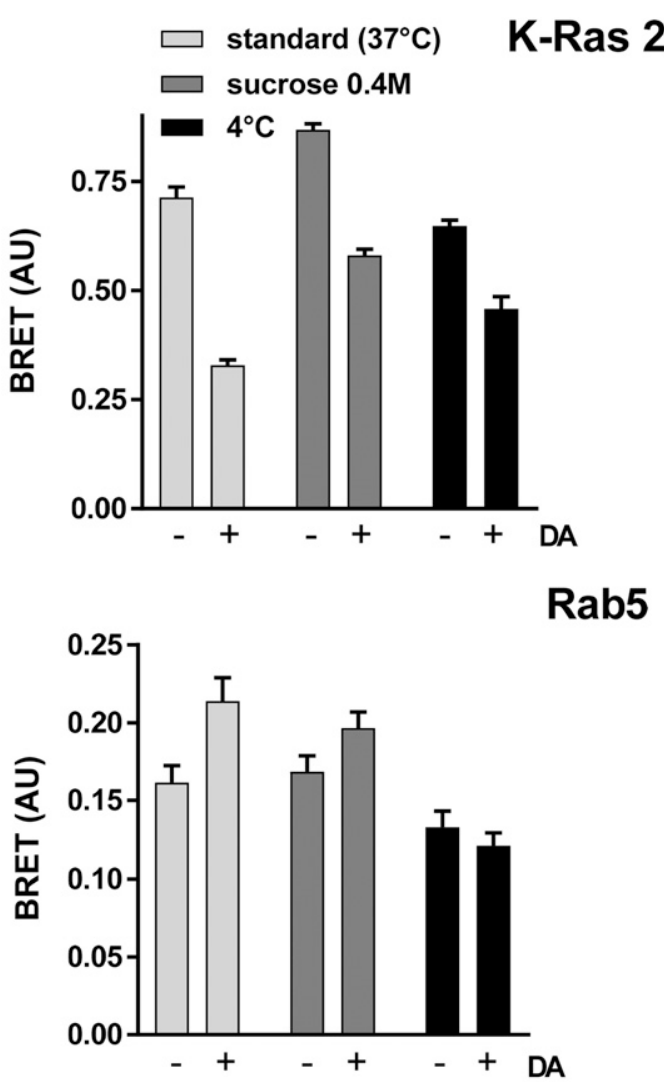

Rab4

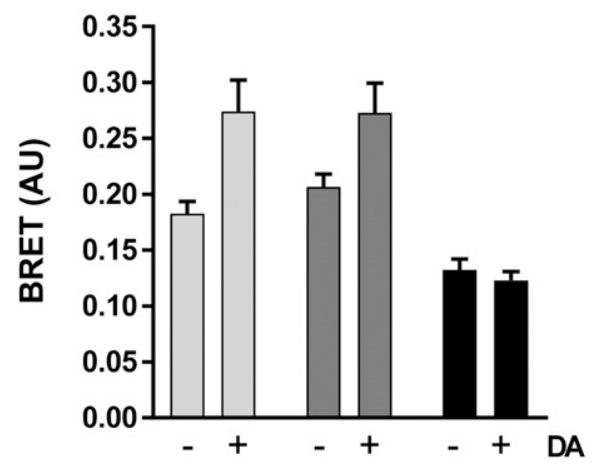

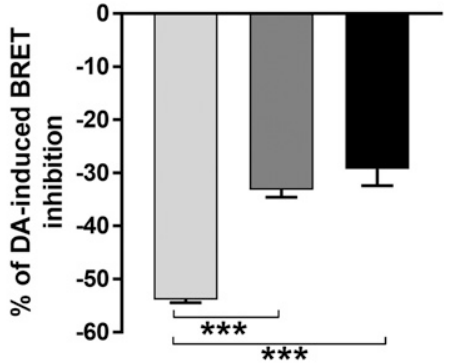

Fig. 4. Endocytosis control experiments. Cells coexpressing luciferase8-tagged D2R/K-Ras2Bct,luciferase8tagged D2R/Rab5, or luciferase8-tagged D2R/Rab4 are preincubated for 15 minutes with $0.4 \mathrm{M}$ sucrose or at $4^{\circ} \mathrm{C}$, then stimulated, or not, by $1 \mu \mathrm{M}$ dopamine (DA). Left panels visualize total BRET signals, which are different for each set of BRET partners. Right panels represent the percentage of BRET change induced by dopamine in each experimental condition, based on the same data as for the left panels. Hypertonic sucrose and temperature block have the expected negative effects on ligand-induced D2R endocytosis, which is mainly clathrindependent. Three independent experiments with duplicate measurements were performed for each couple of BRET partners. One-way ANOVA + post hoc Dunnett were performed for sucrose or $4^{\circ} \mathrm{C}$ versus standard conditions, resulting in $F(2,15)=$ 256.3 with $P<0.001$ for $\mathrm{K}-\operatorname{Ras} 2 \mathrm{~B} ; F(2,15)=926.8$ with $P<0.001$ for Rab5; and $\mathrm{F}(2,15)=139.4$ with $P<0.001$ for Rab4. $* * * P<0.001$. AU, arbitrary units.
In another set of experiments induced by saturating concentrations of ligands, D2R internalization measured by the D2R/K-Ras2Bct BRET assay was compared with the capacity of the receptor to engage in the endocytic pathways, as measured using Rab5 (early endosome), Rab4 (recycling endosome), and Rab7 (late endosome/lysosome) BRET probes (Fig. 7; Table 2). Results showed a common profile of drug responsiveness for the four probes, although a more detailed examination suggests possible discriminatory responses. For instance, the normalized BRET response (vs. dopamine) showed that the Rab5 signal was clearly enhanced versus the K-Ras2Bct response for antipsychotics, with clear D2 partial agonist activities for aripiprazole, bifeprunox, 3PPP(-), RGH188, and SSR181507 (Table 2). Similar observations-but to a lower extent-can be made with Rab4 for the recycling route. Interestingly, the Rab7 probe for late endosome/lysosome localization of the D2R highlighted differential drug responses. Indeed, whereas aripiprazole, $3 \mathrm{PPP}(-)$, and RGH188 again exhibited a similar efficacy as in the K-Ras2Bct assay, bifeprunox and SSR181507 were less active, and sarizotan did not drive the D2R toward the late endosomal/lysosomal compartment (Fig. 7; Table 2). Among antiparkinsonian drugs, bromocriptine was the only molecule whose partial efficacy in the Rab7 assay did not correlate with its high efficacy in the K-Ras2Bct assay. By contrast, roxindole and terguride showed an intermediate efficacy in the Rab7 assay (Fig. 7), in accordance with their partial effect in the K-Ras2Bct assay. Furthermore, the high efficacy of roxindole observed in Rab5 and Rab4 assays suggests this drug might preferentially direct the $\mathrm{D} 2 \mathrm{R}$ toward the recycling route. Finally, 3PPP $(+)$ was efficacious in all Rab probe assays, suggesting again an "antiparkinsonian" profile for this compound, although its low potency for the D2R surely puts a limit on its therapeutic usefulness in this pathology. 

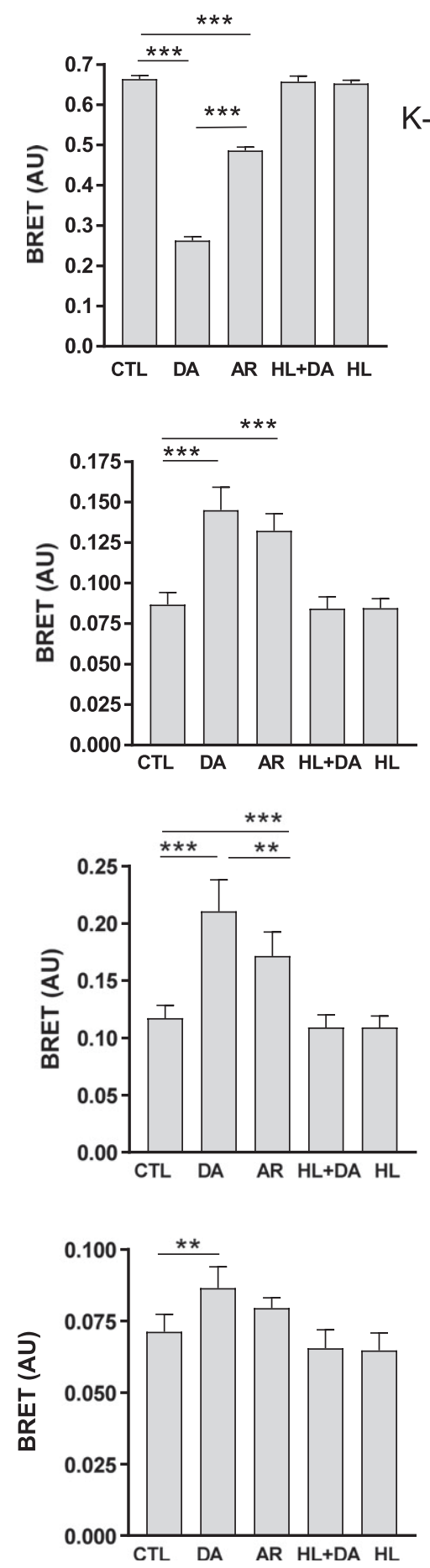

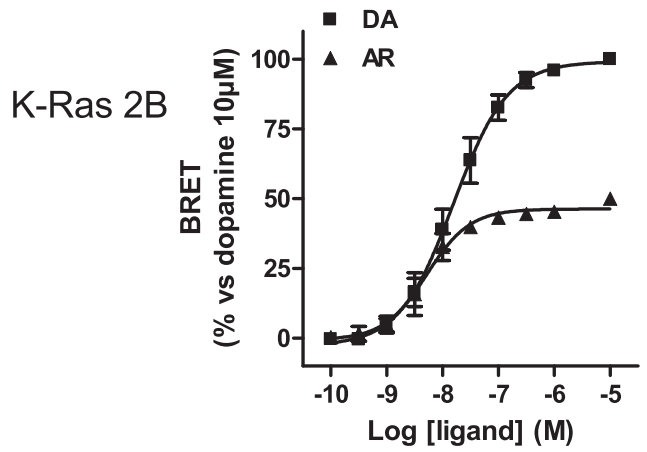

Rab5
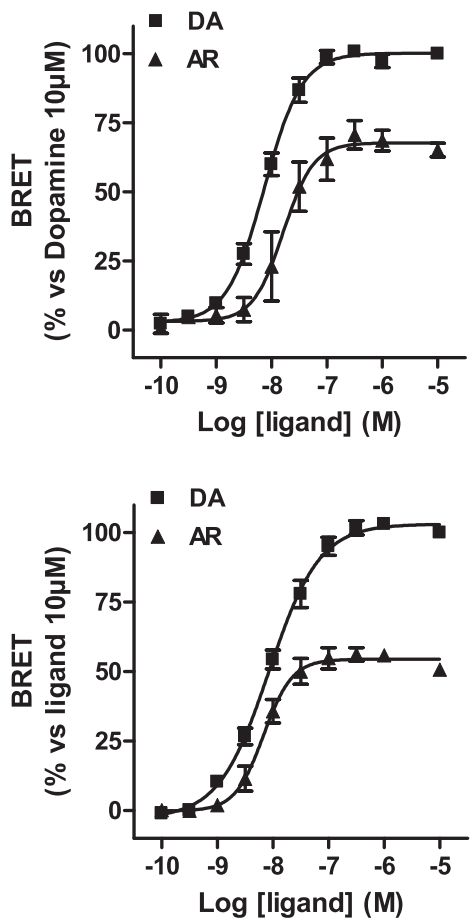

Fig. 5. Validation of experimental pharmacology for each internalization assay. CHO cells expressing D2R/ K-Ras2Bct, D2R/Rab5, D2R/Rab7, or D2R/Rab4 BRET partners were incubated with $1 \mu \mathrm{M}$ dopamine (DA; full agonist), $1 \mu \mathrm{M}$ aripiprazole (AR; partial agonist), $10 \mu \mathrm{M}$ haloperidol $+1 \mu \mathrm{M}$ dopamine (HL+DA), or $10 \mu \mathrm{M}$ haloperidol (HL; antagonist) alone for 1 hour, and BRET signals were measured. The corresponding concentration-response curves to the right are shown for the full agonist dopamine and the partial agonist aripiprazole, expressed as percentage of BRET signal induced by $10 \mu \mathrm{M}$ dopamine after 1 hour. The graphs represent the mean values of three independent experiments, performed for each assay. One-way ANOVA + post hoc Sidak with selected pairs of columns were performed: $F(4,25)=1795$ with $P<0.001$ for K-Ras2B, $F(4,25)=57.58$ with $P<0.001$ for Rab5, $F(4,25)=41.05$ with $P<0.001$ for Rab4, and $F(4,19)=10.39$ with $P<$ 0.001 for Rab7. $* * P<0.01 ; * * * P<0.001$. AU, arbitrary units; CTL, control.

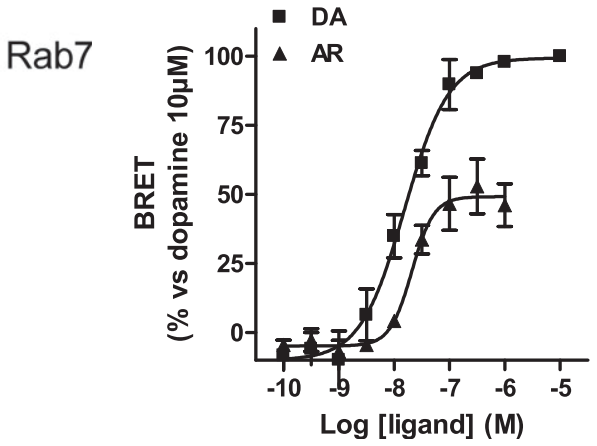

The typical antipsychotic haloperidol as well as the atypical antipsychotics clozapine, its metabolite $N$-desmethyl clozapine, and the more recent SLV313 (adoprazine) did not induce D2R internalization as measured by the K-Ras2Bct assay (Figs. 5 and 7), in accordance with their known D2R antagonist properties. Furthermore, signals for Rab5, Rab4, and especially Rab7 probes were repeatedly negative for these compounds (decreased BRET signal), which might suggest inverse agonist-like behavior.
Arrestin-3 Recruitment and Biased Signaling by D2R Ligands. It is widely accepted that arrestins play a role in GPCR desensitization and internalization by directly interacting with the receptor. Therefore, we included in this study a "classical" BRET-based interaction assay between the D2R and arrestin-3. Concentration-response curves were performed for a large series of D2R ligands (Fig. 6B; Table 1). The D2R antagonists haloperidol, SLV313, clozapine, and its metabolite $N$-desmethyl clozapine were silent for arrestin-3 
A
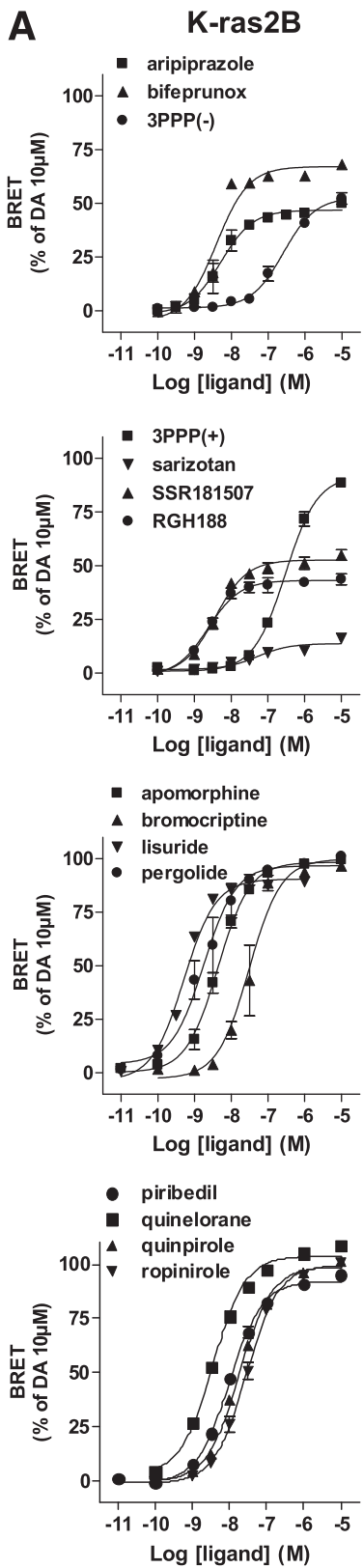

Log [ligand] (M)

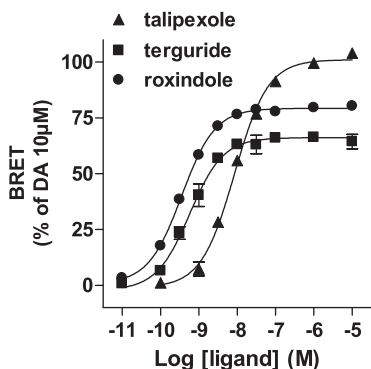

B $\beta$-arrestin

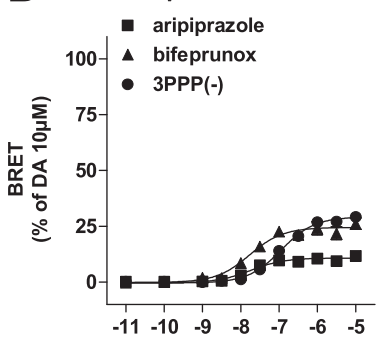

Log [ligand] (M)
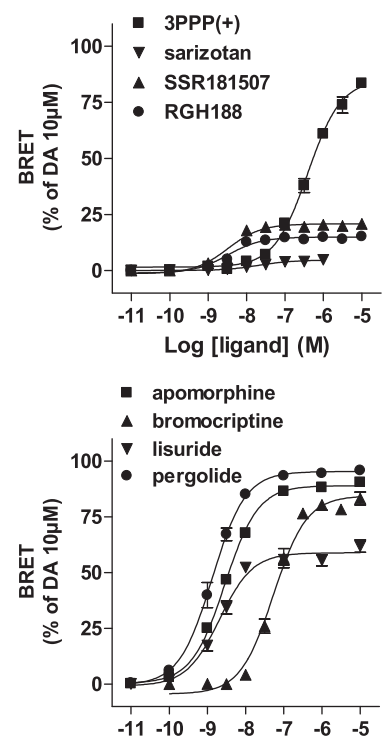

Log [ligand] (M)

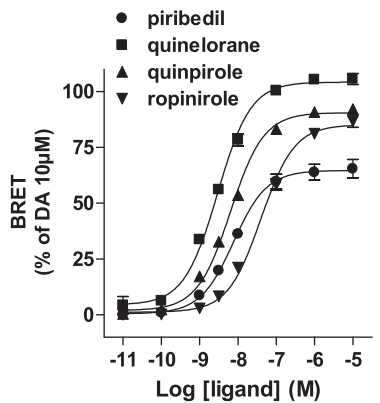

Log [ligand] (M)

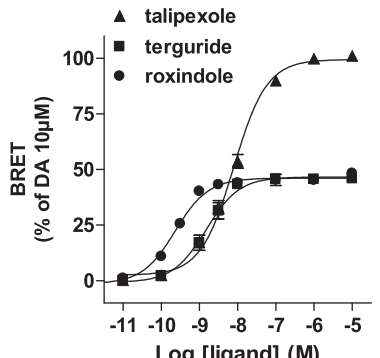

Log [ligand] (M)

Fig. 6. Concentration-response curves for antipsychotic and antiparkinson compounds in the K-Ras2Bct internalization assay (A) and the classic arrestin-3 recruitment BRET assay (B). Cells expressing D2R/K-Ras2Bct BRET partners were incubated for 1 hour with compounds. Data are expressed as percentage of BRET signal induced by $10 \mu \mathrm{M}$ dopamine, which was present in each series. CHO cells expressing D2R/arrestin-3 BRET partners were incubated for 1 hour with compounds. Data are expressed as percentage of BRET signal induced by $10 \mu \mathrm{M}$ dopamine, known to behave as a full agonist in this assay. All compounds were assayed at least three times independently.

recruitment (data not shown). These data allowed us to determine potential biased agonism between arrestin-3 recruitment and internalization (K-Ras2Bct assay) by normalizing both assays with the dopamine effect, according to a recently described procedure (Free et al., 2014). Interestingly, the commercialized antipsychotic drugs aripiprazole and RGH188 and the preclinical antipsychotic bifeprunox preferentially engaged D2R internalization rather than arrestin-3 recruitment (see biased columns in Table 1). By contrast, $3 \mathrm{PPP}(-)$ and the large majority of antiparkinsonian drugs preferentially recruited arrestin- 3 , with the notable exception of lisuride and, to a lesser extent, terguride. Finally, $3 \mathrm{PPP}(+)$, sarizotan, SSR181507, bromocriptine, and ropinirole showed a balanced effect between both pathways.

\section{Discussion}

Internalization of the D2R located at the plasma membrane plays an important role in its downregulation and signaling. Receptors are internalized to endosomes, where some traffic to lysosomes for degradation and some are recycled back to the plasma membrane. Whether the D2R is destined for internalization, recycling, or degradation must ultimately depend on the conformation imposed by its occupying ligand, which induces specific interactions with enzymes causing posttranslational modifications (kinases, ubiquitin system, other) and with other signalosomes. To address ligand-induced D2R intracellular trafficking, we developed new cellular assays based on BRET technology, which can "sense" mean distances between D2R populations and protein marker populations residing at the plasma membrane or on intracellular compartments in live cells.

Our optimization process focused on obtaining conditions for the highest-amplitude changes of BRET signal induced by the natural reference compound dopamine, which, in the case of the K-Ras plasma membrane marker, shows a logical negative amplitude. Given the importance of $\beta$-arrestins and GRKs in the process of GPCR internalization (Ménard et al., 1997; Ferguson, 2001; Reiter and Lefkowitz, 2006) and, more specifically, the importance of arrestin-3 and GRK2 for the D2s receptor (Ito et al., 1999; Oakley et al., 2000; Kim et al., 2001; Heusler et al., 2008), we indeed detected enhanced BRET signals by overexpressing these proteins. Another signal enhancement came from using the truncated version of the K-Ras2B isoform. The $\mathrm{C}$ terminus of this isoform-in contrast to the K-Ras2A isoform-contains a polybasic lysinerich stretch of amino acids that was shown to anchor stably at the plasma membrane by interaction with anionic phospholipids. It also contains a single cysteine residue that can be myristoylated but not palmitoylated (Apolloni et al., 2000; Rocks et al., 2005), bypassing the Golgi where palmitoylation takes place, and directly shuttles to the plasma membrane, avoiding "contaminant" localizations. The truncated form of K-Ras2B lacks its GTPase switch regions and can no longer cycle between its GDP- to GTP-dependent conformations, probably further enhancing its permanent residence at the plasma membrane as we observed by confocal microscopy.

The time courses of the different endocytic BRET assays correspond to what is reported in the literature for D2R endocytosis (Ménard et al., 1997; Heusler et al., 2008). Halflives of the induced BRET signals for the K-Ras, Rab5, and Rab7 markers are in fact very short and contrast with the data 
TABLE 1

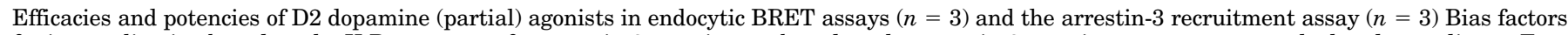

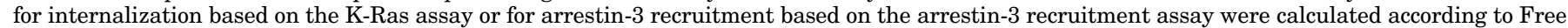
et al. (2014).

\begin{tabular}{|c|c|c|c|c|c|c|}
\hline & \multicolumn{2}{|c|}{ K-Ras2Bct (Internalization) } & \multicolumn{2}{|c|}{ Arrestin-3 } & \multirow{2}{*}{ Bias Internalization } & \multirow{2}{*}{ Bias Arrestin-3 } \\
\hline & Efficacy & Potency & Efficacy & Potency & & \\
\hline Aripiprazole & $46.3 \pm 1.7$ & $8.28 \pm 0.10$ & $10.8 \pm 0.5$ & $7.74 \pm 0.16$ & $7.99^{a}$ & 0.13 \\
\hline Bifeprunox & $67.1 \pm 2.3$ & $8.41 \pm 0.21$ & $24.5 \pm 1.0$ & $7.77 \pm 0.14$ & $6.43^{a}$ & 0.16 \\
\hline $3 \mathrm{PPP}(-)$ & $52.8 \pm 1.8$ & $6.59 \pm 0.07$ & $29.3 \pm 0.6$ & $6.95 \pm 0.06$ & 0.42 & $2.36^{a}$ \\
\hline $3 \mathrm{PPP}(+)$ & $91.8 \pm 1.6$ & $6.52 \pm 0.04$ & $85.1 \pm 1.0$ & $6.41 \pm 0.04$ & 0.75 & 1.34 \\
\hline RGH188 & $43.2 \pm 1.2$ & $8.63 \pm 0.09$ & $15.0 \pm 1.1$ & $8.49 \pm 0.13$ & $2.14^{a}$ & 0.47 \\
\hline Sarizotan & $13.8 \pm 1.1$ & $7.28 \pm 0.21$ & $4.7 \pm 0.2$ & $7.68 \pm 0.11$ & 0.63 & 1.59 \\
\hline SSR181507 & $52.7 \pm 1.3$ & $8.44 \pm 0.16$ & $20.9 \pm 1.5$ & $8.49 \pm 0.12$ & 1.21 & 0.83 \\
\hline Apomorphine & $98.3 \pm 1.6$ & $8.36 \pm 0.05$ & $89.0 \pm 0.6$ & $8.55 \pm 0.02$ & 0.38 & $2.61^{a}$ \\
\hline Bromocriptine & $99.8 \pm 4.6$ & $7.51 \pm 0.11$ & $84.7 \pm 2.3$ & $7.24 \pm 0.06$ & 1.18 & 0.85 \\
\hline Lisuride & $90.5 \pm 1.2$ & $9.29 \pm 0.04$ & $58.9 \pm 1.7$ & $8.68 \pm 0.06$ & $3.36^{a}$ & 0.30 \\
\hline Pergolide & $96.7 \pm 3.2$ & $8.75 \pm 0.12$ & $95.4 \pm 1.7$ & $8.88 \pm 0.04$ & 0.36 & $2.78^{a}$ \\
\hline Piribedil & $92.2 \pm 1.0$ & $8.00 \pm 0.03$ & $64.7 \pm 1.4$ & $8.12 \pm 0.05$ & 0.58 & $1.72^{a}$ \\
\hline Quinelorane & $103.9 \pm 1.1$ & $8.46 \pm 0.07$ & $104.3 \pm 1.7$ & $8.54 \pm 0.04$ & 0.45 & $2.25^{a}$ \\
\hline Quinpirole & $99.0 \pm 1.0$ & $7.75 \pm 0.05$ & $90.6 \pm 1.0$ & $8.19 \pm 0.03$ & 0.21 & $4.69^{a}$ \\
\hline Ropinirole & $99.7 \pm 1.4$ & $7.55 \pm 0.07$ & $85.1 \pm 1.0$ & $7.40 \pm 0.05$ & 0.89 & 1.12 \\
\hline Roxindole & $79.3 \pm 0.4$ & $9.40 \pm 0.05$ & $46.2 \pm 1.7$ & $9.63 \pm 0.07$ & 0.54 & $1.84^{a}$ \\
\hline Talipexole & $101.1 \pm 1.2$ & $8.07 \pm 0.07$ & $99.4 \pm 1.5$ & $8.11 \pm 0.04$ & 0.50 & $2.01^{a}$ \\
\hline Terguride & $66.2 \pm 1.2$ & $9.22 \pm 0.13$ & $46.7 \pm 1.5$ & $8.83 \pm 0.07$ & $1.87^{a}$ & 0.53 \\
\hline Dopamine & $99.2 \pm 3.0$ & $7.81 \pm 0.07$ & $99.3 \pm 1.0$ & $7.54 \pm 0.03$ & 1.00 & 1.00 \\
\hline
\end{tabular}

${ }^{a}$ Significant bias factors.

for the Rab4 marker. One might speculate that the D2R traffics to late endosomes and lysosomes through a fast default pathway after dopamine stimulation, but that a minimal residence time in early endosomes is needed for recycling. A recent study reports the importance of Rab4 in constitutive recycling of the D2R in striatal neurons, whereas slower dopamine-stimulated recycling would be Rab11 sensitive ( $\mathrm{Li}$ et al., 2012).

Many compounds acting on the D2R are used as antipsychotics in schizophrenia and as antiparkinson agents. To provide effective and safe therapies for these pathologies, one must consider their effects on D2R internalization and on the signaling pathways they activate or inhibit. The antipsychotic agents showed overall less efficacy in the K-Ras-, Rab5-, Rab7-, and Rab4-based BRET assays, compared with the antiparkinson group, in accordance with their D2R partial agonist behavior. Clozapine, $N$-desmethyl clozapine, and SLV313 showed no efficacy in the K-Ras assay, but in the Rab5, Rab4, and especially the Rab7 assays, we observed potential inverse agonist-like behavior for these compounds. This tendency to inverse agonist activity detected for clozapine and SLV313 corroborates similar activities for these two drugs at the D2R (long splice form) when measuring potassium channel activity (Heusler et al., 2007). Another explanation for these observations may be that the nonoccupied D2R shows weak constitutive internalization and endocytic trafficking during the 1 hour of the BRET assay, so the antagonists, by stabilizing the D2R at the plasma membrane level, may reveal a negative signal for the sensitive Rab probes.

The antipsychotics sarizotan, bifeprunox, SSR181507, aripiprazole, clozapine, and SLV313 showed the same efficacies in the K-Ras and Rab4 assays than in the internalization assay described by Heusler et al. (2008). However, in the Rab7 assay, their efficacies were weaker, suggesting they might favor the recycling pathway over the lysosomal pathway. The efficacies of the antiparkinson compounds were similar in the
K-Ras, Rab4, and Rab5 assays, again showing lower efficacies in the Rab7 assay.

The amplitude of the K-Ras BRET signals allows establishment of robust concentration-response curves for the active compounds. Compared with potencies obtained in the internalization assay of Heusler et al. (2008), sarizotan, bifeprunox, SSR181507, aripiprazole, and quinpirole showed similar values, but bromocriptine was 30 -fold and $3 \mathrm{PPP}(-)$ was 5-fold less potent in our assay, whereas dopamine was 30fold more potent. Compared with potencies obtained in arrestin-3 recruitment BRET assays for these compounds (Klewe et al., 2008; Allen et al., 2011), we again note similar $\mathrm{pEC}_{50}$ values for compounds tested in both studies, i.e., apomorphine, bromocriptine, pergolide, quinpirole, terguride, ropinirole, and dopamine. The exceptions are $3 \mathrm{PPP}(-)$, which is 10 -fold less potent in our assay, and aripiprazole, which is 30 -fold less potent in the Allen et al. (2011) study, although equipotent in the Klewe et al. (2008) study.

Aripiprazole deserves special attention because it is one of the more recent antipsychotics used, with partial agonist activities for the $\mathrm{D} 2 \mathrm{R}$ and the serotonin $5-\mathrm{HT}_{1 \mathrm{~A}}$ receptor (Burris et al., 2002; Jordan et al., 2002). Aripiprazole was described as a partial agonist for the D2R in several functional assays (Bruins Slot et al., 2006; Urban et al., 2007; Heusler et al., 2008; Klewe et al., 2008; Allen et al., 2011). For all four BRET markers used here, aripiprazole behaved as a partial agonist, with higher efficacies than those reported in arrestin3 BRET assays (Klewe et al., 2008; Allen et al., 2011). We found similar efficacies as those reported by Heusler et al. (2008), who used an antibody-based internalization assay. The potencies of aripiprazole in our assays were somewhat lower than those reported previously (Heusler et al., 2008; Klewe et al., 2008) but significantly higher (30-fold) than the one reported by Allen et al. (2011) in an arrestin-3 BRET assay.

As the arrestin-3 recruitment BRET assay has become one of the standard assays for measuring GPCR internalization, 
K-Ras2B
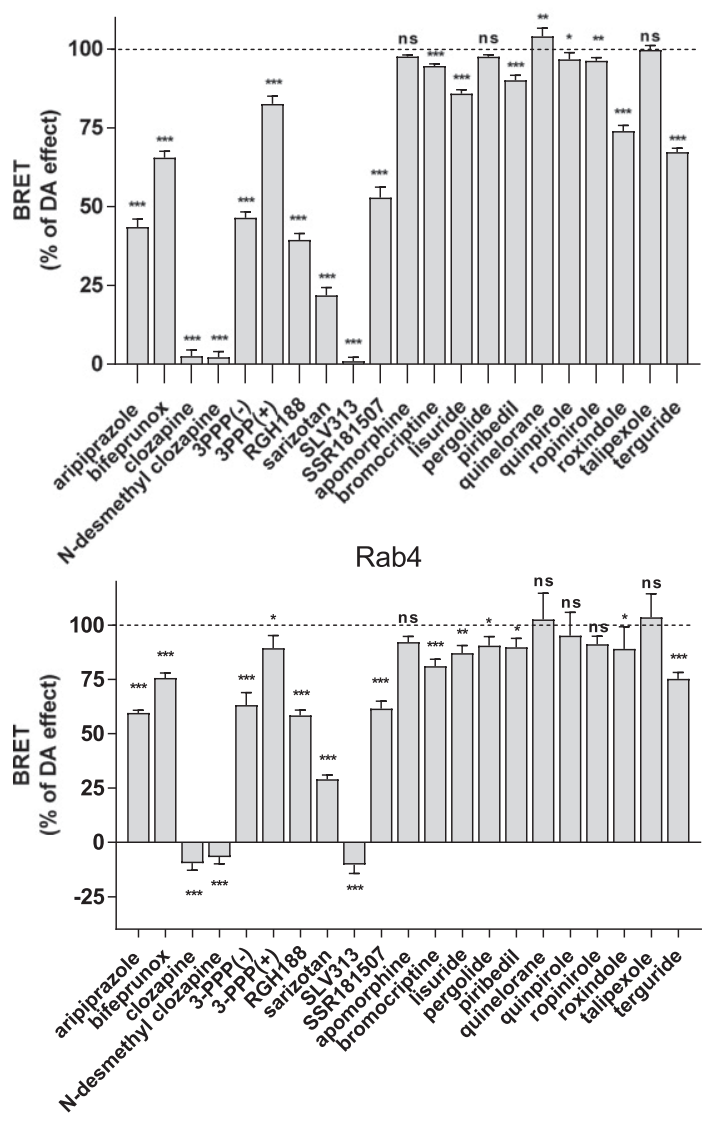

Rab5
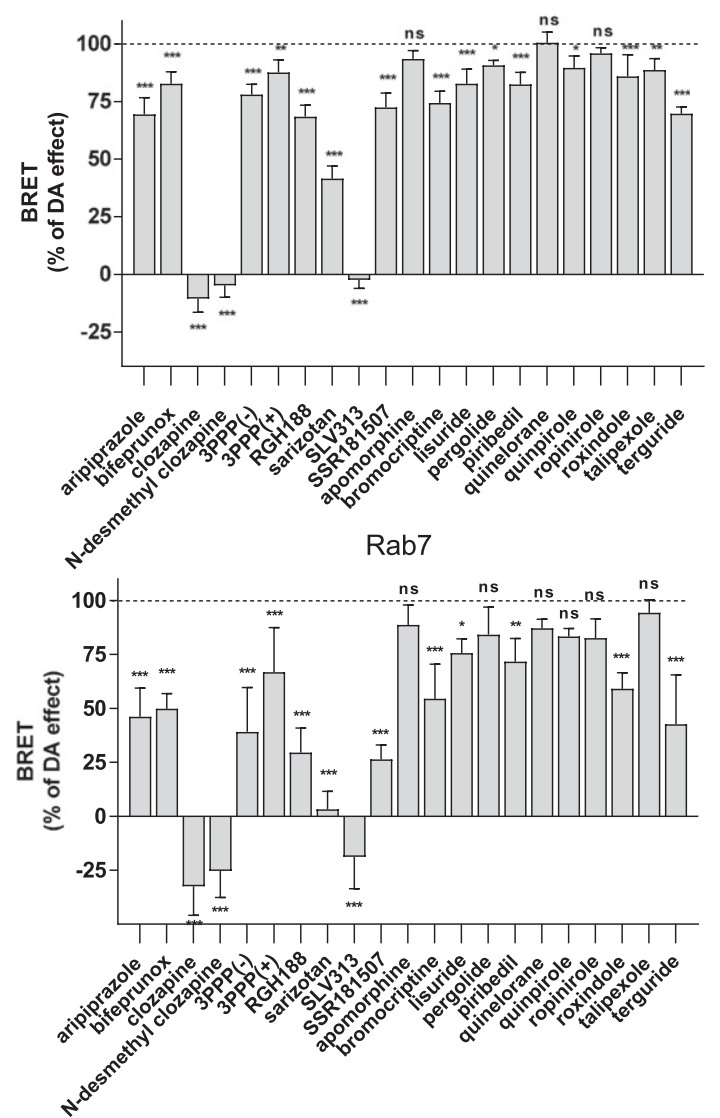

Fig. 7. Efficacies of antipsychotic and antiparkinson compounds with affinity to the D2R. CHO cells expressing D2R/K-Ras2Bct, D2R/Rab5, D2R/Rab4, or D2R/Rab7 BRET partners were incubated with $10 \mu \mathrm{M}$ indicated compounds for 1 hour. Data are expressed as percentage of BRET signal induced by $10 \mu \mathrm{M}$ dopamine and represent the mean \pm S.D. from three independent experiments. One-way ANOVA + post hoc Dunnett were performed for each compound versus dopamine, resulting in $F(22,115)=2136$ with $P<0.001$ for K-Ras $2 \mathrm{~B}, F(22,115)=245.1$ with $P<0.001$ for Rab5, $F(22,115)=243.6$ with $P<0.001$ for Rab4, and $F(22,109)=157.72$ with $P<0.001$ for Rab7. $* P<0.05$; $* * P<0.01$; *** $P<0.001$; ns, not significant.

we decided to perform it in this study as well. The activity of all compounds tested in the arrestin-3 assay is similar to that measured in the K-Ras assay: lower efficacies for the antipsychotics with D2R partial agonist activities as compared with antiparkinsonians, as expected. Thus, these results place the K-Ras assay as a valid alternative for directly

TABLE 2

Efficacies of D2 dopamine (partial) agonists in endocytic BRET assays (Ras and Rabs) and corresponding ratios

\begin{tabular}{|c|c|c|c|c|c|c|c|}
\hline \multirow{2}{*}{ Compound } & \multirow{2}{*}{$\begin{array}{c}\text { K-Ras2Bct } \\
\text { Efficacy }\end{array}$} & \multirow{2}{*}{$\begin{array}{c}\text { Rab5 } \\
\text { Efficacy }\end{array}$} & \multirow{2}{*}{$\begin{array}{c}\text { Rab4 } \\
\text { Efficacy }\end{array}$} & \multirow{2}{*}{$\begin{array}{c}\text { Rab7 } \\
\text { Efficacy }\end{array}$} & \multicolumn{3}{|c|}{ Ratio Rab/Ras } \\
\hline & & & & & Rab5/Ras & Rab4/Ras & Rab7/Ras \\
\hline Aripiprazole & $43.5 \pm 1.0$ & $69.4 \pm 2.9$ & $59.5 \pm 0.5$ & $46.1 \pm 7.7$ & 1.60 & 1.37 & 1.06 \\
\hline Bifeprunox & $65.5 \pm 0.8$ & $82.7 \pm 2.1$ & $75.7 \pm 0.9$ & $41.5 \pm 8.7$ & 1.26 & 1.16 & 0.63 \\
\hline $3 \mathrm{PPP}(-)$ & $46.5 \pm 0.7$ & $78.0 \pm 1.8$ & $63.1 \pm 2.4$ & $39.1 \pm 8.4$ & 1.68 & 1.36 & 0.84 \\
\hline $3 \mathrm{PPP}(+)$ & $82.6 \pm 1.0$ & $87.6 \pm 2.3$ & $89.3 \pm 2.4$ & $66.9 \pm 8.4$ & 1.06 & 1.08 & 0.81 \\
\hline RGH188 & $39.5 \pm 0.8$ & $68.5 \pm 1.9$ & $58.4 \pm 1.0$ & $29.6 \pm 4.7$ & 1.73 & 1.48 & 0.75 \\
\hline Sarizotan & $21.8 \pm 1.0$ & $41.6 \pm 2.3$ & $29.1 \pm 0.8$ & $2.7 \pm 3.1$ & 1.91 & 1.33 & 0.12 \\
\hline SSR181507 & $52.9 \pm 1.3$ & $72.5 \pm 2.5$ & $61.6 \pm 1.4$ & $21.9 \pm 5.0$ & 1.37 & 1.16 & 0.41 \\
\hline Apomorphine & $97.7 \pm 0.2$ & $93.5 \pm 1.5$ & $92.1 \pm 1.1$ & $88.8 \pm 3.7$ & 0.96 & 0.94 & 0.91 \\
\hline Bromocriptine & $94.6 \pm 0.3$ & $74.4 \pm 2.0$ & $81.1 \pm 1.3$ & $54.6 \pm 6.5$ & 0.79 & 0.86 & 0.58 \\
\hline Lisuride & $85.9 \pm 0.5$ & $82.7 \pm 2.6$ & $87.1 \pm 1.4$ & $75.7 \pm 2.7$ & 0.96 & 1.01 & 0.88 \\
\hline Pergolide & $97.6 \pm 0.3$ & $90.7 \pm 0.9$ & $90.4 \pm 1.7$ & $84.2 \pm 5.2$ & 0.93 & 0.93 & 0.86 \\
\hline Piribedil & $90.1 \pm 0.6$ & $82.4 \pm 2.2$ & $89.8 \pm 1.7$ & $71.7 \pm 4.4$ & 0.91 & 1.00 & 0.80 \\
\hline Quinelorane & $104.1 \pm 1.1$ & $100.6 \pm 1.9$ & $102.6 \pm 4.9$ & $87.2 \pm 1.7$ & 0.97 & 0.99 & 0.84 \\
\hline Quinpirole & $96.8 \pm 0.9$ & $89.7 \pm 2.1$ & $95.1 \pm 4.4$ & $83.3 \pm 1.5$ & 0.93 & 0.98 & 0.86 \\
\hline Ropinirole & $96.3 \pm 0.4$ & $87.6 \pm 2.3$ & $91.2 \pm 1.5$ & $82.6 \pm 3.7$ & 0.91 & 0.95 & 0.86 \\
\hline Roxindole & $74.0 \pm 0.7$ & $85.9 \pm 3.8$ & $89.1 \pm 4.1$ & $59.1 \pm 3.1$ & 1.16 & 1.20 & 0.80 \\
\hline Talipexole & $99.8 \pm 0.6$ & $88.7 \pm 1.9$ & $103.5 \pm 4.4$ & $94.3 \pm 2.4$ & 0.89 & 1.04 & 0.94 \\
\hline Terguride & $67.3 \pm 0.5$ & $69.7 \pm 1.2$ & $75.2 \pm 1.2$ & $42.7 \pm 9.3$ & 1.04 & 1.12 & 0.63 \\
\hline Dopamine & 100 & 100 & 100 & 100 & 1.00 & 1.00 & 1.00 \\
\hline
\end{tabular}


measuring internalization of the D2R. Indeed, endocytosis of receptors is best defined by an initial increase of the distance to the plasma membrane, and therefore, we think the K-Ras BRET assay is the best all-round measure for internalization of the D2R. The profiles of the compounds for the other markers (Rab5, Rab7, and Rab4) are similar, with the advantage of the K-Ras assay being its greater signal amplitude. None of the compounds showed a clear and distinctive response toward one of the specific markers Rab7 or Rab4, although in general, the antipsychotics were less efficacious in the Rab7 assay than in the Rab4 assay. This suggests that none of the compounds display a pronounced bias for a specific endocytic route, but rather all somewhat favored the recycling pathway.

Interestingly, we showed a bias between internalization of the D2R and its propension to interact with arrestin-3, depending on the compound tested. Although internalization of D2R was increased by arrestin-3/GRK2 coexpression (see Results herein), this suggests that both pathways are not strictly correlated. Arrestin-3 recruitment participates in antipsychotic efficacy and could also prevent unwanted side effects (Allen et al., 2011), and we confirmed here that antipsychotic drugs such as aripiprazole, bifeprunox, RGH188, and SSR181507 induce arrestin-3 recruitment. However, these drugs preferentially engaged D2R internalization rather than arrestin-3 recruitment, a feature that could participate in their therapeutic effect by desensitization of the D2R, which is overactivated in schizophrenic patients. Interestingly, 3PPP and sarizotan, which failed as antipsychotic drugs in clinical trials, possess an inverse profile, i.e., they are biased toward arrestin-3 recruitment. Furthermore, most antiparkinsonian drugs directed toward arrestin-3 recruitment, suggesting that this recruitment may reflect a general feature of antiparkinsonian therapeutic efficacy. Moreover, both compounds terguride and lisuride, which failed as antiparkinsonian drugs and have been repositioned as antihyperprolactinemia drugs, induce a preference for D2R internalization.

Direct determination of D2R internalization using K-Ras as well as its endocytic routes with Rab probes is of interest for deciphering the intracellular trafficking of $\mathrm{D} 2 \mathrm{R}$ activation by specific ligands. These methodologies could also be applied to other GPCRs, and even to other types of receptors. Still, other applications are possible: the knowledge that a receptor takes a defined endocytic pathway imposed by a specific ligand is of great importance in the field of antibody-drug-conjugates for oncology, for example, where the successful subcellular delivery and cleavage of a cytotoxic payload may depend on the destiny of the receptor.

\section{Acknowledgments}

The authors thank Dr. A. Auclair for excellent statistical advice.

\section{Authorship Contributions}

Participated in research design: De Vries, Cussac.

Conducted experiments: De Vries, Finana, Cathala, Ronsin. Contributed new reagents or analytic tools: Finana, Cathala. Performed data analysis: De Vries, Finana, Ronsin, Cussac.

Wrote or contributed to the writing of the manuscript: De Vries, Finana, Ronsin, Cussac.

\section{References}

Allen JA, Yost JM, Setola V, Chen X, Sassano MF, Chen M, Peterson S, Yadav PN, Huang XP, Feng B, et al. (2011) Discovery of $\beta$-arrestin-biased dopamine $D_{2}$ ligands for probing signal transduction pathways essential for antipsychotic efficacy. Proc Natl Acad Sci USA 108:18488-18493.

Alvarez-Curto E, Inoue A, Jenkins L, Raihan SZ, Prihandoko R, Tobin AB, and Milligan G (2016) Targeted elimination of $G$ proteins and arrestins defines their specific contributions to both intensity and duration of $\mathrm{G}$ protein-coupled receptor signaling. $J$ Biol Chem 291:27147-27159.

Apolloni A, Prior IA, Lindsay M, Parton RG, and Hancock JF (2000) H-ras but not K-ras traffics to the plasma membrane through the exocytic pathway. Mol Cell Biol 20:2475-2487.

Barr FA (2013) Review series: Rab GTPases and membrane identity: causal or inconsequential? J Cell Biol 202:191-199.

Beaulieu JM, Gainetdinov RR, and Caron MG (2007) The Akt-GSK-3 signaling cascade in the actions of dopamine. Trends Pharmacol Sci 28:166-172.

Beaulieu JM, Marion S, Rodriguiz RM, Medvedev IO, Sotnikova TD, Ghisi V, Wetsel WC, Lefkowitz RJ, Gainetdinov RR, and Caron MG (2008) A beta-arrestin 2 signaling complex mediates lithium action on behavior. Cell 132:125-136.

Bruins Slot LA, De Vries L, Newman-Tancredi A, and Cussac D (2006) Differential profile of antipsychotics at serotonin $5-\mathrm{HT}_{1 \mathrm{~A}}$ and dopamine $\mathrm{D}_{2 \mathrm{~S}}$ receptors coupled to extracellular signal-regulated kinase. Eur J Pharmacol 534:63-70.

Bucci C, Parton RG, Mather IH, Stunnenberg H, Simons K, Hoflack B, and Zerial M (1992) The small GTPase rab5 functions as a regulatory factor in the early endocytic pathway. Cell 70:715-728.

Burris KD, Molski TF, Xu C, Ryan E, Tottori K, Kikuchi T, Yocca FD, and Molinoff PB (2002) Aripiprazole, a novel antipsychotic, is a high-affinity partial agonist at human dopamine D2 receptors. J Pharmacol Exp Ther 302:381-389.

Clayton CC, Donthamsetti P, Lambert NA, Javitch JA, and Neve KA (2014) Mutation of three residues in the third intracellular loop of the dopamine D2 receptor creates an internalization-defective receptor. J Biol Chem 289:33663-33675.

Ferguson SS (2001) Evolving concepts in G protein-coupled receptor endocytosis: the role in receptor desensitization and signaling. Pharmacol Rev 53:1-24.

Free RB, Chun LS, Moritz AE, Miller BN, Doyle TB, Conroy JL, Padron A, Meade JA, Xiao J, Hu X, et al. (2014) Discovery and characterization of a G protein-biased agonist that inhibits $\beta$-arrestin recruitment to the D2 dopamine receptor. Mol Pharmacol 86:96-105.

Grundmann M, Merten N, Malfacini D, Inoue A, Preis P, Simon K, Rüttiger N, Ziegler N, Benkel T, Schmitt NK, et al. (2018) Lack of beta-arrestin signaling in the absence of active G proteins. Nat Commun 9:341.

Heusler P, Newman-Tancredi A, Castro-Fernandez A, and Cussac D (2007) Differential agonist and inverse agonist profile of antipsychotics at D2L receptors coupled to GIRK potassium channels. Neuropharmacology 52:1106-1113.

Heusler P, Newman-Tancredi A, Loock T, and Cussac D (2008) Antipsychotics differ in their ability to internalise human dopamine $\mathrm{D}_{2 \mathrm{~S}}$ and human serotonin $5-\mathrm{HT}_{1 \mathrm{~A}}$ receptors in HEK293 cells. Eur $J$ Pharmacol 581:37-46.

Ito K, Haga T, Lameh J, and Sadee W (1999) Sequestration of dopamine $\mathrm{D}_{2}$ receptors depends on overexpression of G-protein-coupled kinases 2 or 5. Eur J Biochem 260 596-602.

Jordan S, Koprivica V, Chen R, Tottori K, Kikuchi T, and Altar CA (2002) The antipsychotic aripiprazole is a potent, partial agonist at the human $5-\mathrm{HT}_{1 \mathrm{~A}}$ receptor. Eur J Pharmacol 441:137-140.

Kim KM, Valenzano KJ, Robinson SR, Yao WD, Barak LS, and Caron MG (2001) Differential regulation of the dopamine D2 and D3 receptors by G protein-coupled receptor kinases and beta-arrestins. J Biol Chem 276:37409-37414.

Klewe IV, Nielsen SM, Tarpø L, Urizar E, Dipace C, Javitch JA, Gether U, Egebjerg $\mathrm{J}$, and Christensen KV (2008) Recruitment of $\beta$-arrestin2 to the dopamine D2 receptor: insights into anti-psychotic and anti-parkinsonian drug receptor signaling. Neuropharmacology 54:1215-1222.

Kurko D, Kapui Z, Nagy J, Lendvai B, and Kolok S (2014) Analysis of functional selectivity through $\mathrm{G}$ protein-dependent and -independent signaling pathways at the adrenergic $\alpha\left({ }_{2 \mathrm{C}}\right)$ receptor. Brain Res Bull 107:89-101.

Lan TH, Kuravi S, and Lambert NA (2011) Internalization dissociates $\beta_{2}$-adrenergic receptors. PLoS One 6:e17361.

Li Y, Roy BD, Wang W, Zhang L, Zhang L, Sampson SB, Yang Y, and Lin DT (2012) Identification of two functionally distinct endosomal recycling pathways for dopamine $\mathrm{D}_{2}$ receptor. $J$ Neurosci 32:7178-7190.

Loening AM, Fenn TD, Wu AM, and Gambhir SS (2006) Consensus guided mutagenesis of Renilla luciferase yields enhanced stability and light output. Protein Eng Des Sel 19:391-400.

Luttrell LM, Maudsley S, and Bohn LM (2015) Fulfilling the promise of "biased" G protein-coupled receptor agonism. Mol Pharmacol 88:579-588.

Marchese A, Paing MM, Temple BRS, and Trejo J (2008) G protein-coupled receptor sorting to endosomes and lysosomes. Annu Rev Pharmacol Toxicol 48: $601-629$

Masri B, Salahpour A, Didriksen M, Ghisi V, Beaulieu JM, Gainetdinov RR, and Caron MG (2008) Antagonism of dopamine D2 receptor/beta-arrestin 2 interaction is a common property of clinically effective antipsychotics. Proc Natl Acad Sci USA 105:13656-13661.

Ménard L, Ferguson SS, Zhang J, Lin FT, Lefkowitz RJ, Caron MG, and Barak LS (1997) Synergistic regulation of $\beta_{2}$-adrenergic receptor sequestration: intracellular complement of $\beta$-adrenergic receptor kinase and $\beta$-arrestin determine kinetics of internalization. Mol Pharmacol 51:800-808.

Oakley RH, Laporte SA, Holt JA, Caron MG, and Barak LS (2000) Differential affinities of visual arrestin, beta arrestin1, and beta arrestin2 for G proteincoupled receptors delineate two major classes of receptors. J Biol Chem $\mathbf{2 7 5}$ 17201-17210

O'Hayre M, Eichel K, Avino S, Zhoa X, Steffen DJ, Feng X, Kawakami K, Aoki J, Messer K, Sunahara R, et al. (2017) Genetic evidence that $\beta$-arrestins are dispensable for the initiation of $\beta 2$-adrenergic receptor signaling to ERK. Sci Signal 10 Available from: 10.1126/scisignal.aal3395.

Park SM, Chen M, Schmerberg CM, Dulman RS, Rodriguiz RM, Caron MG, Jin J, and Wetsel WC (2015) Effects of $\beta$-arrestin-biased dopamine D2 receptor 
ligands on schizophrenia-like behavior in hypoglutamatergic mice. Neuropsychopharmcology 41:704-715 Available from: 10.1038/npp.2015.196.

Pauwels PJ, Finana F, Tardif S, Wurch T, and Colpaert FC (2001) Dynamic dopamine-antagonist interactions at recombinant human dopamine $\mathrm{D}$ (2short) receptor: dopamine-bound versus antagonist-bound receptor states. J Pharmacol Exp Ther 297:133-140.

Peterson SM, Pack TF, Wilkins AD, Urs NM, Urban DJ, Bass CE, Lichtarge O, and Caron MG (2015) Elucidation of G-protein and $\beta$-arrestin functional selectivity at the dopamine D2 receptor. Proc Natl Acad Sci USA 112:7097-7102.

Reiter E and Lefkowitz RJ (2006) GRKs and beta-arrestins: roles in receptor silencing, trafficking and signaling. Trends Endocrinol Metab 17:159-165.

Rink J, Ghigo E, Kalaidzidis Y, and Zerial M (2005) Rab conversion as a mechanism of progression from early to late endosomes. Cell 122:735-749.

Rocks O, Peyker A, Kahms M, Verveer PJ, Koerner C, Lumbierres M, Kuhlmann J, Waldmann $\mathrm{H}$, Wittinghofer A, and Bastiaens PI (2005) An acylation cycle regulates localization and activity of palmitoylated Ras isoforms. Science $\mathbf{3 0 7}$ : 1746-1752.
Stallaert W, Christopoulos A, and Bouvier M (2011) Ligand functional selectivity and quantitative pharmacology at G protein-coupled receptors. Expert Opin Drug Discov 6:811-825.

Tsai SJ (2004) Dopamine receptor downregulation: an alternative strategy for schizophrenia treatment. Med Hypotheses 63:1047-1050.

Urban JD, Vargas GA, von Zastrow M, and Mailman RB (2007) Aripiprazole has functionally selective actions at dopamine D2 receptor-mediated signaling pathways. Neuropsychopharmacology 32:67-77.

van der Sluijs P, Hull M, Webster P, Mâle P, Goud B, and Mellman I (1992) The small GTP-binding protein rab4 controls an early sorting event on the endocytic pathway. Cell 70:729-740.

Address correspondence to: Dr. Luc De Vries, Institut de Recherche Pierre Fabre, CEPC Campans - Belair de Campans, 81106 Castres, France. E-mail: luc.de.vries@pierre-fabre.com 